This is a post-print (post-refreeing) version of the paper.

Please find the final, printed version of the paper at

https://www.tandfonline.com/doi/full/10.1080/00221686.2017.1289259?src=recsys

Please cite this paper as:

Bregoli, F., Bateman, A., \& Medina, V. (2017). Tsunamis generated by fast granular landslides: 3D experiments and empirical predictors. Journal of Hydraulic Research, 55(6), 743-758.

A discussion on this paper is available at

https://iahr.tandfonline.com/doi/full/10.1080/00221686.2017.1399939?

src=recsys\#.XfZsNmRKhPY

Frederic M. Evers, Helge Fuchs \& Willi H. Hager (2018) Tsunamis generated by fast granular landslides: 3D experiments and empirical predictors By Francesco Bregoli, Allen Bateman and Vicente Medina, Journal of Hydraulic Research, 56:4, 581-582, DOI:

$10.1080 / 00221686.2017 .1399939$

And the closure is available at

https://iahr.tandfonline.com/doi/full/10.1080/00221686.2017.1399940\#.XfZrW2RKhPY

Francesco Bregoli, Allen Bateman \& Vicente Medina (2018) Closure to "Tsunamis generated by fast granular landslides: 3D experiments and empirical predictors" by FRANCESCO BREGOLI, ALLEN BATEMAN and VICENTE MEDINA, J. Hydraulic Res. 1-16. doi:10.1080/00221686.2017. 1289259, Journal of Hydraulic Research, 56:4, 583-584, DOI: $10.1080 / 00221686.2017 .1399940$ 


\title{
Tsunamis generated by fast granular landslides: 3D experiments and empirical predictors
}

\author{
FRANCESCO BREGOLI (Di $\dagger^{\dagger}$, Postdoctoral Researcher, Catalan Institute for Water Research (ICRA), Girona, Spain \\ Email: francesco.bregoli@gits.ws (author for correspondence)
}

ALLEN BATEMAN PINZÓN (D) (IAHR Member), Professor, Department of Hydraulic, Marine, and Environmental Engineering, Sediment Transport Research Group (GITS), Universitat Politècnica de Catalunya - BarcelonaTech (UPC), Barcelona, Spain

Email: allen.bateman@gits.ws

VICENTE MEDINA, Associate Professor, Department of Hydraulic, Marine, and Environmental Engineering, Universitat Politècnica de Catalunya - BarcelonaTech (UPC), Sediment Transport Research Group (GITS), Barcelona, Spain

Email: vicente.medina@gits.ws

\section{ABSTRACT}

Landslides falling into water bodies can generate impulsive waves, which are considered as tsunamis. The propagating wave may be highly destructive for hydraulic structures, civil infrastructure and people living along the shorelines. A facility to study this phenomenon was set up in the laboratory of the Technical University of Catalonia. The set-up consists of a new device releasing granular material at high velocity into a wave basin. A system employing laser sheets, high-speed and high-definition cameras was designed to accurately measure the high velocity and geometry of the sliding mass as well as the produced water displacement in time and space. The analysis of experimental data helped to develop empirical relationships linking the landslide parameters with the produced wave amplitude, propagation features and energy, which are useful tools for the hazard assessment. The empirical relationships were successfully tested in the case of the 2007 event that occurred in Chehalis Lake (Canada).

Keywords: Chehalis Lake; impulse wave; landslide tsunami; natural hazard; physical modelling; wave generation

\section{Introduction}

A tsunami can be potentially triggered by any mass move-ment able to displace a large mass of water. A specific tsunami is generated when a sufficient quantity of solid - or a liquid and solid mixture - slides into or through a reservoir, a nat-ural lake, a fjord, a river or the sea. The momentum of the sliding mass is transferred to the mass of water turning into a set of giant waves able to travel relatively large distances and finally run-up the shorelines. This phenomenon, known as an impulse wave (Kamphuis \& Bowering, 1970), landslide tsunami (Mader, 1999; Ward \& Day, 2001) or displacement wave (Hermanns, L'Heureux, \& Blikra, 2013), can be highly destructive and difficult to predict as witnessed by past events in which thousands of people perished (Roberts, McKillop, Hermanns, Clague, \& Oppikofer, 2014). A tsunamigenic landslide may be composed of blocks or loose granular material of different densities and with the presence or absence of water in the basis of its formation. The landslide can start initially above the water (sub-aerial landslide), partially underwater or totally underwater. Normally a sub-aerial landslide is more destructive, the slide having the possibility to accelerate considerably along the slope. An underwater landslide, frequent in seas, often involves a larger amount of sliding material compared with the subaerial process, but usually produces smaller wave height and run-up.

The present work focuses on tsunamis provoked by granu-lar sub-aerial landslides. Although they have a high destructive potential, landslides may produce a tsunami wave that decays more rapidly than earthquake tsunamis (Heller \& Hager, 2010). This suggests a different scale of the processes and the forces involved: crustal blocks that move during large earthquakes are often vastly larger than any landslide (Bardet, Synolakis, Davies, Imamura, \& Okal, 2003). However, relatively close

Received 4 November 2015; accepted 24 January 2017/Currently open for discussion.

${ }^{\dagger}$ Formerly at: Sediment Transport Research Group (GITS), Department of Hydraulic, Marine, and Environmental Engineering, Universitat Politècnica de Catalunya - BarcelonaTech (UPC), Barcelona, Spain 
to impact and especially in confined or narrow water bodies, the waves can produce very large run-up, destroying the shoreline or easily overtopping dams (Panizzo, De Girolamo, \& Petaccia, 2005b). Historical examples testify the power of this behaviour. However the limited number of events entails that aftermath analyses are not sufficient to properly predict future effects. For this reason experimental studies have been carried out by different researchers in the last four decades. The experiments concern rigid bodies (e.g. Ataie-Ashtiani \& NikKhah, 2008; Carvalho \& Antunes do Carmo, 2007; Heller \& Spinneken, 2013; Kamphuis \& Bowering, 1970; Panizzo et al., 2005b) or granular material (e.g. Fritz, Hager, \& Minor, 2004; Huber, 1980; Mohammed \& Fritz, 2012) plunging in wave channels (two-dimensional, 2D) or in wave basins (threedimensional, 3D). Numerical models have received a boost in the last 20 years for their versatility (e.g. Abadie, Morichon, Grilli, \& Glockner, 2010; Quecedo, Pastor, \& Herreros, 2004; Vacondio, Mignosa, \& Pagani, 2013; Zhao, Utili, \& Crosta, 2016). But the complexity of simulating the 3D phenomenon involving the solid, liquid and gaseous phases means that experimental works are still attractive either to describe the processes or to provide data for model validation. Deformability is one of the essential features peculiar to a granular mass. This property is usually not easy to take into account, as the mass rapidly changes its shape during the slide's progress. But, at the same time, deformability plays an important role in the triggering behaviour of the process (Fritz, Hager, \& Minor, 2003b; Mohammed \& Fritz, 2012). Moreover the effects of 3D wave propagation in a basin seem to be of primary importance as it can explain - at the first instance - the over-estimation of empirical formulations such as are produced by experimental studies made on wave channels (Panizzo et al., 2005b).

On the basis of the previous observations, in the laboratory of the Sediment Transport Research Group (GITS) of the Technical University of Catalonia (UPC) a new experimental device to

study landslide tsunamis has been set up. It has been designed to simulate the behaviour of landslide tsunamis, e.g. their generation and propagation. Special attention was given to reproducing the $3 \mathrm{D}$ granular landslide deformation and the $3 \mathrm{D}$ wave propa-gation in a wave tank. The experiments have been planned to fill previous research gaps concerning high velocity and low angles of landslide impact and a continuous spatial representation of wave propagation rather than spot measurements. In civil engi-neering the task of predicting the effect of natural hazards is fundamental.

Thus, the aim of the present work is to provide empirical predictors able to quantify the possible hazard due to tsunamis generated by landslides, useful in risk assessment frameworks. To this effect a total number of 41 experiments have been carried on in order to define empirical relationships between the landslides features and the produced wave characteristics. Finally the empirical predictors have been tested on a welldocumented real case: the 2007 Chehalis Lake event in Canada.
The experimental device, the empirical predictors as well as the tests on the mentioned events are presented and discussed.

\section{Experimental set-up}

The experimental set-up is located in the fluvial- morphodynamics laboratory of the Sediment Transport Research Group (GITS), at BarcelonaTech. The device is composed by a landslide generator, a wave tank and a measuring system necessary for the observation of the process. The landslide generator consists of a steep flume, with slope $\alpha$ variable from 0 to $27.8^{\circ}$, designed to release the granular material into a rectangular water basin, placed at the exit of the channel. It was found necessary to force the landslide to reach a high velocity, and thus a high landslide Froude number F, so as to achieve similarity with real events occurring in nature. Therefore, to give to the granular material a sufficient velocity, a system was developed, able to achieve high-speed mass movement and, at the same time, permitting the measurement of the main landslide parameters. The solution was obtained through the fabrication of a wheeled steel box, sliding on rails fixed to the lateral walls of the flume (Fig. 1). The rails have a very low degree of surface roughness and deformability. The box, filled with gravel, obtains sufficient acceleration along the $6.20 \mathrm{~m}$ of rail length. At the end of the flume, a high-resistance shock absorber (hydraulic piston) instantly stops the box, thus forcing the opening of the flaps and the release of the granular material. The released material plunges into the basin, creates a crater and a splash (Fig. 2) and eventually triggers a wave train. In its underwater motion the simulated landslide propagates along a wedge having the same roughness of the tank bottom. Once the experiment is concluded, the box is filled again for the next experiment with the selected amount of gravel and is lifted back to its initial position by means of a winch.

The system allows for the independent modification of the landslide main parameters. The mass $m_{s}$ can be changed by choosing the amount of gravel. The geometry of the landslide can be varied in its initial length, thickness and width within the box maximum internal dimensions: $1.00 \times 0.30 \times 0.34 \mathrm{~m}$ (length $\times$ height $\times$ width). The angle of impact $\alpha$ can be adjusted by varying the flume slope, between $15^{\circ}$ and $27.8^{\circ}$. The velocity of the landslide at impact can be varied by dropping the box from different heights, thus changing its initial poten-tial energy. The rectangular wave tank has a length $L$ of $4.10 \mathrm{~m}$ and a width $W$ of $2.45 \mathrm{~m}$. The tank water depth $h_{w}$ can be set, if required, to a maximum of $0.60 \mathrm{~m}$. The selected granular mate-rial is composed of a white gravel (Fig. 2a) of $d_{50}$ $=16.9 \mathrm{~mm}$, bulk density $\rho_{s, b u l k}=1692 \mathrm{kgm}^{-3}$ and a basal friction angle between gravel and slope of $\varphi_{s-b}=30^{\circ}$, evaluated here with laboratory tests under dry conditions. Heller and Hager (2010) concluded that the grain size of the sliding mass has a negligible effect on the impulse wave features. Therefore the consequence of varying the sediment sizes is not investigated here. 
(a)

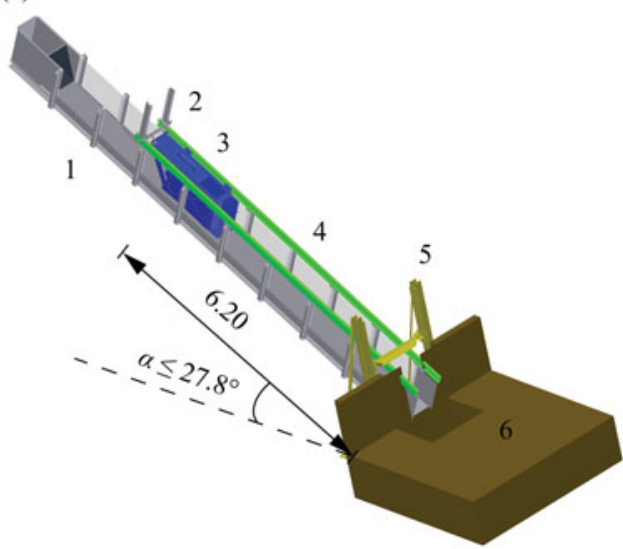

(b)

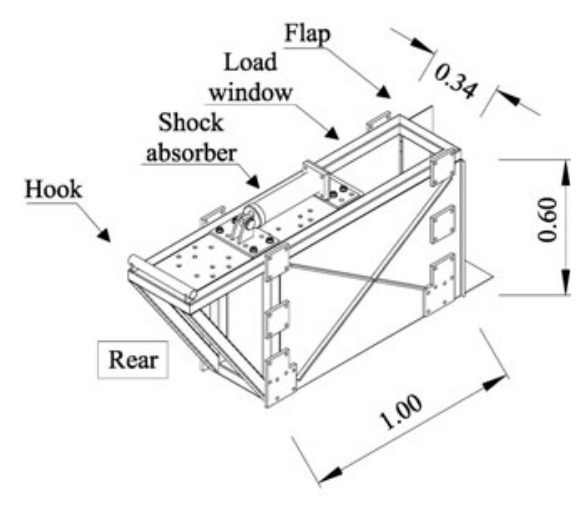

Figure 1 Landslide generator: (a) 3D view of the flume (1) with triggering hook (2), sliding box (3), rails (4), brake bridge structure (5) and a partial representation of wave basin (6); (b) sketch of a sliding box (measurements in metres)
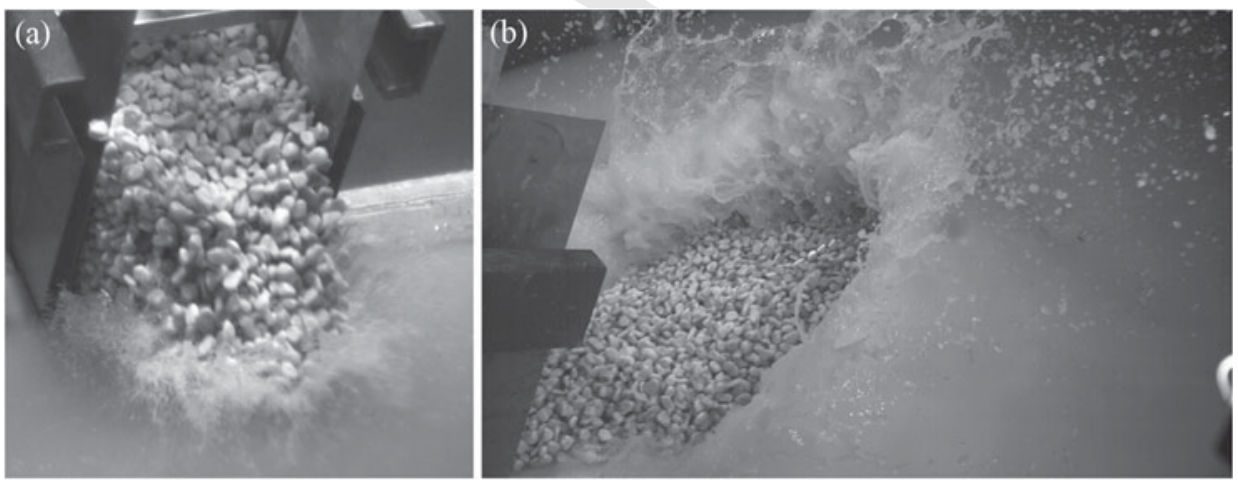

Figure 2 Granular material released in water basin after flaps open. Photos taken with the HS camera recording at $640 \mathrm{f} \mathrm{s}^{-1}$ : (a) front view of granular material entering water; (b) rear view of granular material sliding into water, creating crater and splash

\section{Dimensional analysis and scale effects}

The model is based on Froude similitude. The governing parameters and the identified dependent variables of the phenomenon are shown in Fig. 3. Following the $\Pi$-theorem, any dimensionless property $\Pi$ of the wave, and thus any

\section{(a) Landslide}

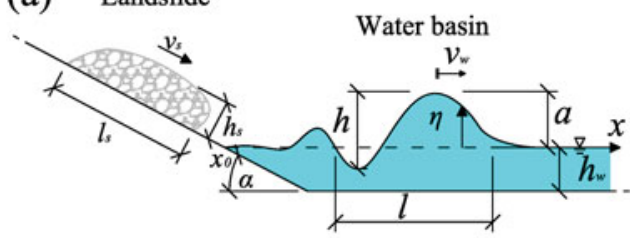

(b)

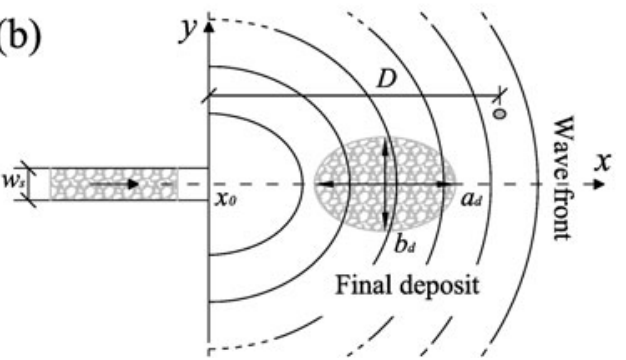

Figure 3 Sketch of the phenomenon with coordinate system and parameters involved: (a) lateral view; (b) aerial view dependent dimensionless variable being investigated here, may be expressed as:

$$
\begin{aligned}
\Pi= & f\left(\frac{h_{s}}{h_{w}}, \frac{l_{s}}{h_{w}}, \frac{w_{s}}{h_{w}}, \frac{V_{s}}{h_{w}{ }^{3}}, \frac{m_{s}}{h_{w}{ }^{3} \rho_{w}}, \frac{\rho_{s, \text { bulk }}}{\rho_{w}},\right. \\
& \left.\times \frac{v_{s}}{\left(g h_{w}\right)^{1 / 2}}, \alpha, t\left(\frac{g}{h_{w}}\right)^{1 / 2}, \frac{x}{h_{w}}, \frac{y}{h_{w}}\right)
\end{aligned}
$$

where $h_{s}$ is the average thickness of landslide at impact, $l_{s}$ is the length of landslide at impact, $w_{s}$ is the width of landslide at impact, $V_{S}$ is the volume of landslide at impact, $\rho_{s, b u l k}$ is the bulk density of landslide, $\rho_{w}$ is the density of water, $v_{s}$ is the average velocity of landslide at impact, $g$ is the gravity acceleration, $t$ is the elapsed time from impact, $x$ is the distance from impact along sliding direction and $y$ is the lateral distance from sliding direction. In order to define the dimensionless variables, one can see that in Eq. (1) the three chosen repeating parameters are $h_{w}, \rho_{w}$ and $g$. The wave length $l$ and the wave height $h$ are not analysed within this study because the wave reflections early compromise the clean wave signal.

The dimensionless numbers of interest when considering scale effects of gravity, viscosity and surface tension on this specific physical model are respectively the landslide Froude number $\mathrm{F}$, the Reynolds number $\mathrm{R}$ and the Weber number $\mathrm{W}$. 
Cauchy number is not taken into account since water is considered an incompressible fluid. The dimensionless numbers are hereinafter presented together with the ranges investigated in this research:

$$
\begin{aligned}
1.91 \leq \mathrm{F} & =v_{s}\left(g h_{w}\right)^{-1 / 2} \leq 4.17 \\
2.80 \times 10^{5} \leq \mathrm{R} & =\rho_{w} g^{1 / 2} h_{w}^{3 / 2} \mu_{w}^{-1} \leq 3.92 \times 10^{5} \\
5.39 \times 10^{3} \leq \mathrm{W} & =\rho_{w} g h_{w}^{2} \sigma_{w}^{-1} \leq 8.42 \times 10^{3}
\end{aligned}
$$

where $\mu_{w}=10^{-3} \mathrm{~kg} \mathrm{~m}^{-1} \mathrm{~s}^{-1}$ is the dynamic water viscosity and $\sigma_{w}=7.28 \times 10^{-2} \mathrm{~kg} \mathrm{~s}^{-2}$ is the water surface tension. In Eq. (1) one can see the presence of $F$, while $R$ and $W$ are omitted. Indeed, taking into account the range of explored parameters of our physical model, the effects of dynamic viscosity and surface tension of water are sufficiently small to be neglected when comparing with inertial forces. This fact is proved by Eqs (3) and (4). A discussion on scale effects in impulse wave physical models have been presented by Heller, Hager, and Minor (2008) and Heller (2011), giving the rule of thumb of $h_{w} \geq 0.20 \mathrm{~m}$, which is equivalent to $R \geq 2.80 \times 10^{5}$ and $\mathrm{W} \geq 5.39 \times 10^{4}$. Following Keulegan (1948), wave dumping in the laboratory due to boundary layer effects and fluid viscosity is accounted in less than $4 \%$ for a propagating solitary wave of amplitude $a=0.1 \mathrm{~m}$ within a wave tank of $h_{w}>0.1 \mathrm{~m}$. Thus the explored range of $0.20 \mathrm{~m} \leq h_{w} \leq 0.25 \mathrm{~m}$ entails negligible viscous effects. The experiments that were carried out do not cover the full ranges of parameters potentially provided by the set-up. However the full ranges will be explored in future studies.

\section{Measuring system}

A new measuring system, employing techniques of computer vision, was set up to observe the granular mass movement and the wave propagation at high resolution. Computer vision systems are artificial systems that obtain information from images (Shapiro \& Stockman, 2001). Computer vision techniques have been recently applied in hydraulic experimental applications (e.g. Erikson \& Hanson, 2005; Wang, Chen, \& Liao, 2012; Yao $\& \mathrm{Wu}, 2005)$. Computer vision applied to particle image velocimetry (PIV) has been employed in experiments of landslide tsunamis to evaluate the velocity field in the impact zone (e.g. Fritz, Hager, \& Minor, 2003a; Sælevik, Jensen, \& Pedersen, 2009).

The system employed in this work uses images from an array of digital video cameras and a set of processing algorithms. In designing the measuring method the authors intended to pursue the measurement of the produced waves quasi-continuously in time and space so as to avoid the classical spatially discontinuous measurements produced by probes. The measurement of the geometry and velocity evolution of the landslide is achieved by recording, with a high speed (HS) camera at 500 frames per second ( $\mathrm{f} \mathrm{s}^{-1}$ ), the released material upon the exit of the sliding box. The landslide is marked at the centreline of the propagating path within the area of impact with a $1 \mathrm{~W}$ powered green laser diode, collimated to a sheet of $1 \mathrm{~cm}$ width. The white colour of the gravel reflects the laser light. A number of laser sheets project lines on the water surface. The green laser previously mentioned for the gravel measurement, having a collimated longitude of $4.20 \mathrm{~m}$, is able to properly mark the centreline of the wave basin. Six red lasers collimated to sheets of $1 \mathrm{~cm}$ width mark transversally the wave basin (Fig. 4a). The water has been previously loaded with a small amount of kaolin that colours the fluid white, reflecting the lasers at water surface (Fig. 4b). The amount of kaolin has been set at $5 \%$ of water volume. This kaolin content does not alter the viscosity of the water. Kaolin is odourless and does not dissolve in water, thus it can be recovered easily after drying the tank. Three high definition (HD) video cameras focus on the water tank, recording from different points of view the produced water displacement at the laser sheets with a frame rate of $50 \mathrm{f} \mathrm{s}^{-1}$. In Fig. 4a one can observe the hatched areas representing the respective angles of view of the two main cameras employed: the HD camera $\mathrm{C}$, and the HS camera. The two angles of view overlap at the landslide entrance. This is necessary to connect the observations of camera $\mathrm{C}$ and the HS (a)

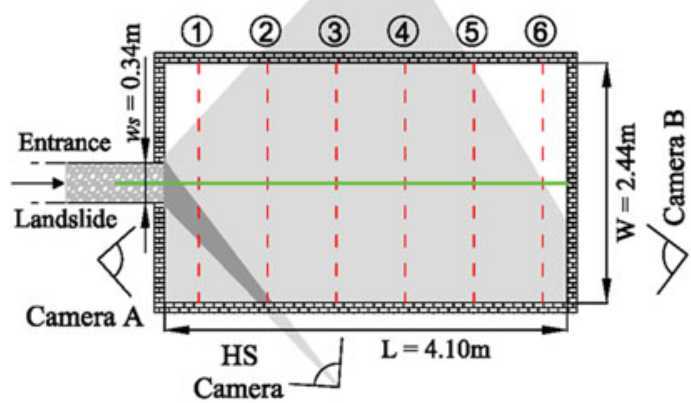

(b)

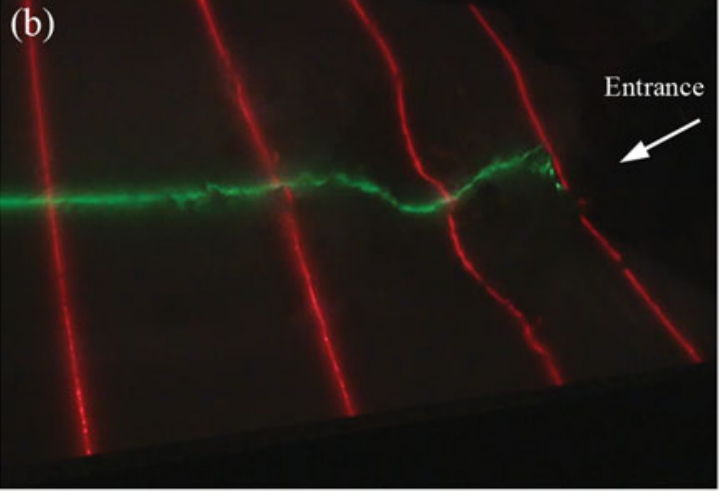

Figure 4 Laser grid on wave basin: (a) laser sheets positions in water tank and point of view of the three HD cameras A, B and C focusing on water tank, and the HS camera recording the granular material (hatched areas represent angles of view of camera C and HS camera); (b) example of water surface displacement recorded by camera $\mathrm{C}$ at $0.7 \mathrm{~s}$ after slide impact 
441 camera at the instant of landslide impact. Cameras A and B are used in limited experiments to observe the lateral propagation of the wave front as well as the wave reflection with lateral walls.

Through a calibration process employing a mathematicalgeometrical transformation algorithm created ad hoc by the GITS team (Bateman, Granados, Medina, Velasco, \& Nalesso, 2006), the metrical measurement of the laser lines is achieved. The measurements are performed on the laser lines drawing the intersection between the laser planes and the surfaces to be measured. Thus the calibration of images is exactly applied to the plane of each laser sheet where the calibration panel must be aligned. Due to the particular condition of the laboratory set-up, the calibration tool has been significantly enhanced to achieve a correct measurement although using highly distorted lens and in presence of perspective distortion. To this effect the tool employs the nonlinear method of Tsai (1987) including optimization of lens distortion, and a new method able to achieve the calibration in case of pronounced non parallel condition between the plan of the camera sensor and the plan of calibration. An example of calibration method and result is shown in the Supplemental Material.

Due to the novelty of the described application, errors and uncertainty of the measurement system have been assessed. The system has a maximum resolution of $10^{-5} \mathrm{~m}$, an accuracy of \pm 5 $\times 10^{-4} \mathrm{~m}$ and a precision of $\pm 5 \times 10^{-4} \mathrm{~m}$. The laser sheets have a thickness of $0.01 \mathrm{~m}$. Therefore the operator that holds the calibration panel may introduce an accidental rota-tion or translation respect to the laser sheet centre. A sensitivity analysis was performed artificially introducing the maximum systematic errors related to these accidental misalignments. The maximum uncertainty in landslide measurement is estimated in the range of $\pm 2 \%$ in the horizontal direction and $\pm 15 \%$ in the vertical direction, while for the water surface displacement it is estimated in the range of $\pm 1 \%$ in the horizontal direction and \pm $15 \%$ in the vertical direction. The calculated uncertain-ties include the accuracy and precision of the measurement tool. In order to eliminate the effects of splash and drops along the measuring sections, appropriate morphological operations on each frame as well as lowpass filters on the resulting signal are applied. This measuring technique differs from PIV applications. PIV permits the evaluation of the velocity field along a fluid section illuminated by a laser sheet. However the measurement is limited to a small window of observation. The technique used in this work permits a wider window of observation, but the measurement is limited to the water surface rather than the velocity field of the fluid mass.

The final deposit, having a quasi-elliptical form, was synthetically measured in its major axis $a_{d}$ and minor axis $b_{d}$, in order to take into account the deformations suffered. When the observation was possible, the distance from impact of the farthest grain $D$ was recorded. This provides a measure of the water surface surfing or jumping by the particle that was observed by Mazzanti and De Blasio (2011).

\section{Experimental results}

For this study, the main parameters of the granular slide to be measured at impact are: mean velocity $v_{s}$, mean thickness $h_{s}$ and length $l_{s}$. The width at impact is constant. The evolution of landslide velocity $v_{s}(t)$ and thickness $h_{s}(t)$ in time are measured inside an observation control volume of fixed length and centred at $x_{0}$. Within the same control volume the averaged velocity $v_{s}$ and thickness $h_{s}$ related to the centroid of the mass at impact are measured. The total length of the landslide, $l_{s}$, is also measured. The implemented measuring algorithm recognizes and enumerates blobs within each frame. In computer vision, blob detection methods are aimed at detecting regions in a digital image that differ in properties, in this case brightness, compared to surrounding regions. Identifying blobs is here useful in recognizing and following an object moving in sub-sequential frames. This technique is called particle image tracking and is here employed to follow frame by frame each illuminated grain of the granular mass. Thus the velocity is calculated for each grain knowing the displacement of its centroid and the time interval $\Delta t_{H S}=1 / 500 \mathrm{~s}$ given by the frame rate of the HS camera. The mean velocity and vertical position of all the illuminated grains travelling inside the control volume is calculated and then averaged within each time step $t_{i}$ to obtain the bulk average values of velocity $v_{s}\left(t_{i}\right)$ and thickness $h_{s}\left(t_{i}\right)$. Starting from this principle, in researching the averaged properties $\left(v_{s}, h_{s}\right.$ and $\left.l_{s}\right)$ of the landslide, an average on the entire granular mass passing through the control volume is calculated considering the total mass $M$ and momentum $r$ per unit width and unit density as follows:

$$
\begin{aligned}
M & =\Delta t_{H S} \sum_{i}\left(h_{s}\left(t_{i}\right) \cdot v_{s}\left(t_{i}\right)\right) \\
r & =\Delta t_{H S} \sum_{i}\left(h_{s}\left(t_{i}\right) \cdot v_{s}^{2}\left(t_{i}\right)\right) \\
h_{S} & =M\left(\Delta t_{H S} \sum_{i} v_{s}\left(t_{i}\right)\right)^{-1} \\
v_{s} & =r M^{-1} \\
l_{s} & \approx \Delta t_{H S} \sum_{i} v_{s}\left(t_{i}\right)
\end{aligned}
$$

Contrary to what is observed in sliding blocks, here the form and velocity of a deformable sliding mass change point by point, being influenced by the basal frictional forces along the wedge and the tank bottom and the interaction with the water body. The material at impact is stretched longitudinally (Fig. 5) and expanded laterally during the process as shown by the final deposit form. Similar observations are given by Mohammed and Fritz (2012). The velocity decreases (Fig. 5). As explained earlier, here mean values of thickness $h_{s}$ and velocity $v_{s}$ at impact have been selected as representative of the mass at impact, although values at landslide front are usually higher. The investigated ranges of landslide parameters 

eters

\begin{tabular}{lrrrrrr}
\hline & $h_{s} / h_{w}$ & $l_{s} / h_{w}$ & $\mathrm{~F}$ & $a_{d} / h_{w}$ & $b_{d} / h_{w}$ & $D / h_{w}$ \\
\hline Max. & 1.26 & 8.24 & 4.17 & 10.00 & 8.61 & 16.06 \\
Min. & 0.38 & 4.24 & 1.91 & 5.00 & 3.80 & 9.20 \\
\hline
\end{tabular}

at impact are: $\alpha=15^{\circ}, 27.8^{\circ} ; 0.09 \mathrm{~m} \leq h_{s} \leq 0.25 \mathrm{~m} ; 2.99 \mathrm{~m}$ $\mathrm{s}^{-1} \leq v_{s} \leq 5.85 \mathrm{~m} \mathrm{~s}^{-1} ; 0.85 \mathrm{~m} \leq l_{s} \leq 2.06 \mathrm{~m} ; w_{s}=0.34 \mathrm{~m}$; $50 \mathrm{~kg} \leq m_{s} \leq 143 \mathrm{~kg}$. The ranges of observed values of landslide final deposit are: $1.03 \mathrm{~m} \leq a_{d} \leq 1.80 \mathrm{~m} ; 0.95 \mathrm{~m} \leq$ $b_{d} \leq 1.59 \mathrm{~m}, 2.00 \mathrm{~m} \leq D \leq 2.98 \mathrm{~m}$. Ranges of selected dimensionless parameters are collated in Table 1 . In producing predictive empirical formulas and evaluating the energy conversion $\epsilon$ between landslide energy and wave energy, the kinetic energy of the landslide at impact $E_{s, k i n}=1 / 2 m_{s} v_{s}^{2}$ is used as representative of the landslide. The range of the investigated landslide kinetic energies is: $271.9 \mathrm{~J} \leq E_{s, k i n} \leq 2109.8 \mathrm{~J}$.

The water surface elevation $\eta$ is measured along the direction $x$ for each time step $\Delta t_{H D}=1 / 50 \mathrm{~s}$ given by the frame rate of the HD camera (Fig. 6). The first frame where the contact of landslide with water is detected corresponds to the frame of initial time $t=0$. Due to the limited size of the wave basin, wave reflection was a major issue. It has been possible to estimate the time taken by the lateral reflection to arrive back to the longitudinal centreline of the tank (Figs 6 and 7) due to the observations along the transverse section (red lasers). It was found that the first crest signal is clean. However the wave length $l$ and the wave height $h$ are not analysed in the present study, because wave reflections partially compromise their measurement. Moreover, using the measurement on the transverse sections of the basin, it was possible to assess that the formed wave had a marked elliptical front form with the longest axis along the $x$ axis. The ratio between the shortest and the longest axis was assessed to be 0.75 on average. In the example of Fig. $8 \mathrm{~b}$ it is possible to observe the main measurements performed for the frame reported in Fig. 8a. The location of the first crest's peak gives the wave amplitude $a$ and its location $x$ in time. The celerity of the first wave crest $v_{w}$ is measured frame by frame following the crest peak. Two key points are recognized: the first up-crossing point $P_{1}$ and the first down-crossing point $P_{2}$. The first crest longitude $l_{1 c}$ and its subtended area are measured between $P_{1}$ and $P_{2}$ (Fig. 8b). Within the subtended area of the first crest, the first wave crest volume $V_{w}$ and potential
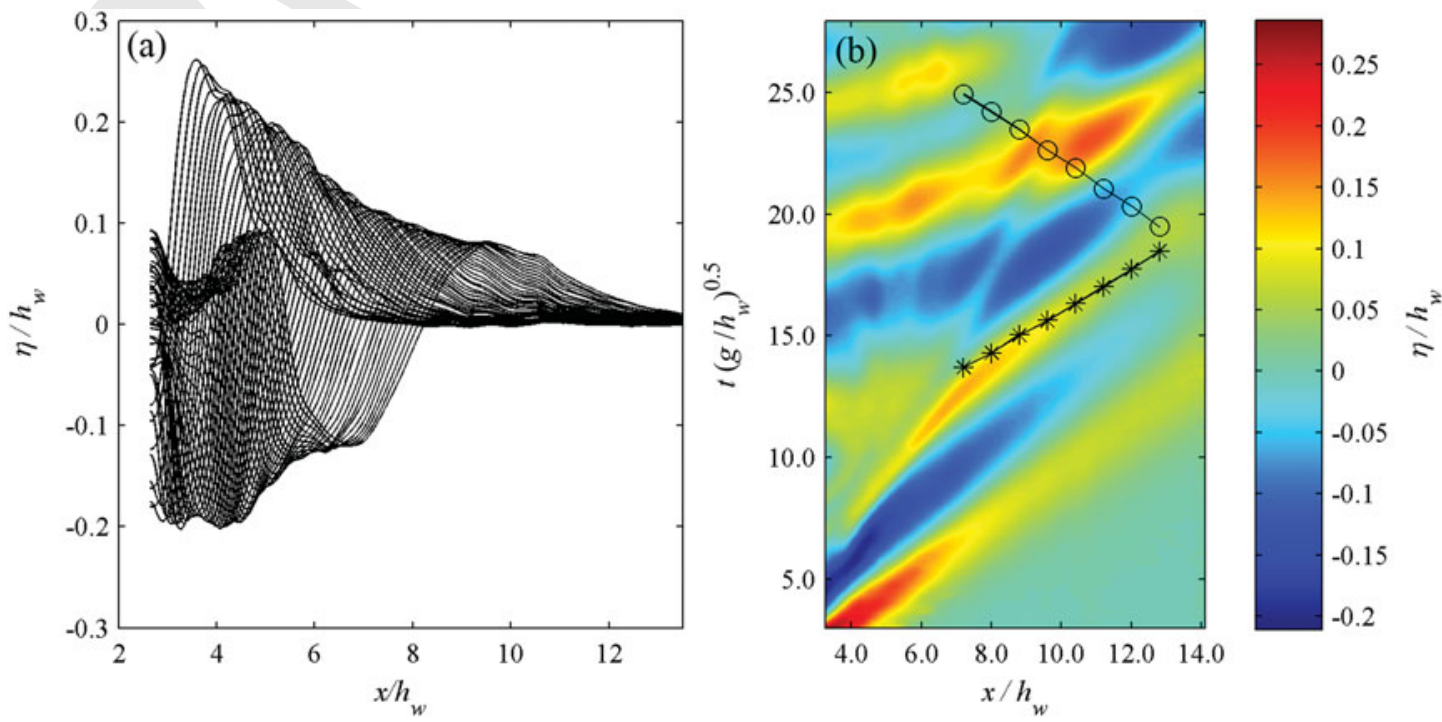

Figure 6 Example of wave profiles series for same experiment of Fig. 5: (a) water profiles along $x$ for 50 time steps; (b) interpolated representation of 250 time steps with estimated frontal (line and circles) and lateral (line and asterisks) wave reflection arrival to centreline of tank by means of elliptical front 

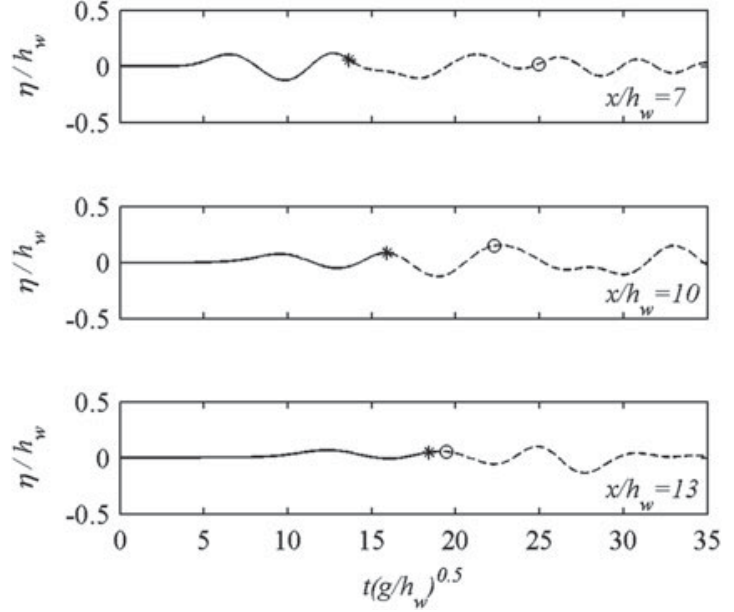

Figure 7 Water displacement time series at different selected spots for 676 the same experiment of Figs 5 and 6. Circles represent the estimated frontal wave reflection arrival; asterisks represent estimated lateral wave reflection arrival to centreline of tank by means of elliptical front; dashed lines represent compromised signals

energy $E_{w, p o t}$ integrated along the semi-circular wave front is calculated as follows:

$$
\begin{aligned}
V_{w} & =n \int_{x=P_{1}}^{x=P_{2}}(\pi x \eta) \mathrm{d} x \\
E_{w, p o t}(x) & =n \frac{1}{2} \rho_{w} g \int_{x=P_{1}}^{x=P_{2}}\left(\pi x \eta^{2}\right) \mathrm{d} x
\end{aligned}
$$

where $n$ is the factor of shape correction due to the elliptical wave front, i.e. 0.75 from the analysis of the lateral wave propagation. $\eta$ is considered constant along the semi-circular wave front. Some authors (e.g. Mohammed \& Fritz, 2012) propose an amplitude attenuation along the angular direction proportional to the cosine. However, due to the lack of significant radial observation, no angular attenuation has been considered in this work.
The maximum window of observation of the camera $\mathrm{C}$ is 0 $<x<3.75 \mathrm{~m}$, which corresponds in dimensionless form to $0<$ $x / h_{w}<18.75$. However, in Fig. $8 \mathrm{~b}$ it is possible to observe that the measurement of camera $\mathrm{C}$ starts from $x=1 \mathrm{~m}$ : the area of measurement was masked close to impact because of splash interferences. Thus the window of observation, constrained by the splash on one side and by the camera angle on the other side, is limited to a width ranging from $2.25 \mathrm{~m}$ to $2.75 \mathrm{~m}$, depending on the experiment. The camera field misses, in any case, a section of about $0.50 \mathrm{~m}$ before the end of the tank. However, the visual angle of the camera cannot be moved: it is required that the camera films, as a minimum, the landslide entrance in order to determine $t=0$.

The first wave crest amplitude is measured considering the envelope curve of the maxima of the first wave crest propagating along $x$ and $t$. The decrease in amplitude was approximated by dimensionless exponential functions that describe properly the amplitude decay in space and time. The measured amplitudes of waves fall in the range $a / h_{w}=[0.05 ; 0.76]$. The celerity of the first wave peak, $v_{w}$, was measured along $x$ to observe its spatial and temporal variation. $v_{w}$ remains almost constant along the observed distance exceeding the celerity of linear shallow water waves by $8 \%$ on average. This means that the first crest celerity is higher than the one approximated by the shallow water theory. The standard deviation of the ratio $v_{w} / c$ is 0.11 . The value of $v_{w}$ is lower than the celerity of solitary waves $c_{\text {sol }}=\left[g\left(h_{w}+a\right)\right]^{1 / 2}$ by $5 \%$ in average. This means that the celerity of the first $c=\left(g h_{w}\right)^{1 / 2}$ crest is lower than the one approximated by the solitary wave theory. The standard deviation of the ratio $v_{w} / c_{\text {sol }}$ is 0.06 (Table 2). Thus both approximations work well, but the approximation of $c_{\text {sol }}$ is chosen for safety reasons. Similar results on the first crest celerity of a landslide tsunami have been previously described by other authors both in 2D and 3D experiments (e.g. Fritz et al., 2004; Kamphuis \& Bowering, 1970; Mohammed \& Fritz, 2012). Assessing that the celerity of the landslide-generated tsunami is comparable with the celerity of solitary waves is the most important feature for early warning
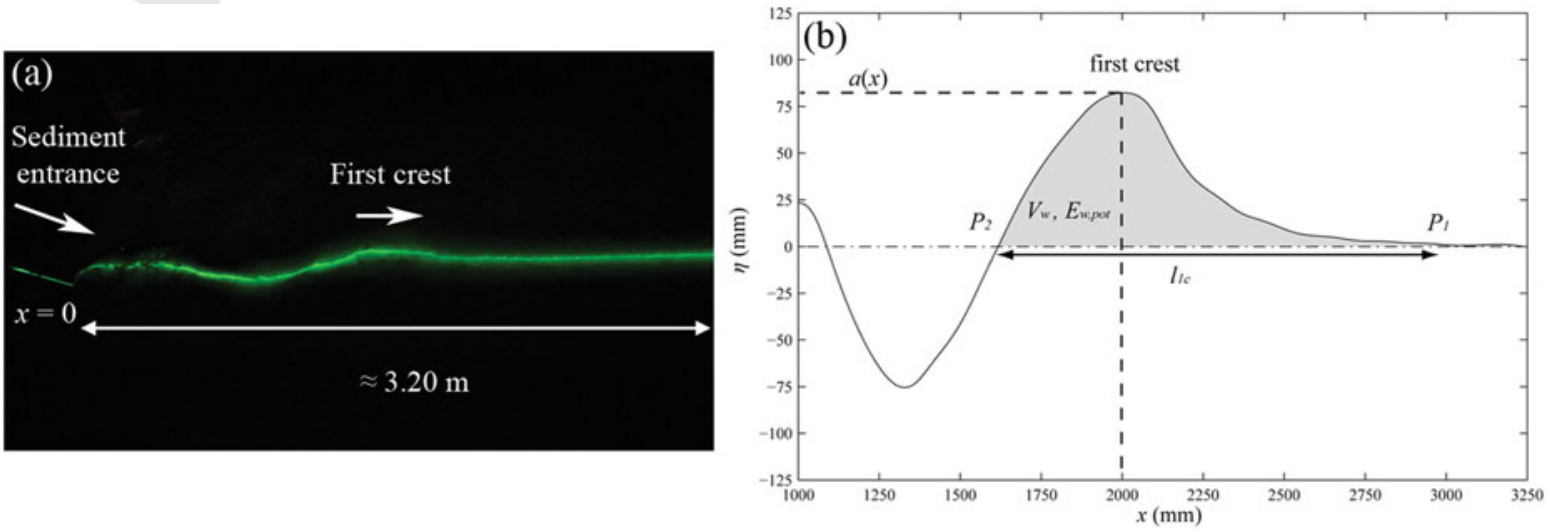

Figure 8 Example of measurement of a camera $\mathrm{C}$ frame: (a) frame at $t=0.9 \mathrm{~s}$ after impact; (b) result of measurement after image treatment and signal filtering, for frame in Fig. 8a. Dash-dot line represents still water level. Solid line represents water surface displacement $\eta$. First crest amplitude $a(x)$ and position $x$ are identified by seeking the first wave crest maximum. Grey area is the 2D integrating area under first crest, where volume $V_{w}$ and potential energy $E_{w, p o t}$ of wave are measured 
Table 2 Ranges of selected wave dimensionless measured values, energy conversion between landslides and waves and wave potential energy equipartition

\begin{tabular}{lcccccccc}
\hline & $a_{\max } / h_{w}$ & $x_{\max } / h_{w}$ & $t_{\max } \cdot(g / h)^{0.5}$ & $a / h_{w}$ & $v_{w} / c$ & $v_{w} / c_{\text {sol }}$ & $E_{w, p o t}\left(x_{\max }\right) / E_{s, k i n}$ & $E_{w, p o t}\left(x_{\max }\right) / E_{w, p o t}\left(x_{f i n}\right)$ \\
\hline Max. & 0.76 & 9.405 & 5.183 & 0.76 & 1.36 & 1.12 & 0.081 & 2.55 \\
Min. & 0.26 & 3.580 & 3.132 & 0.05 & 0.98 & 0.88 & 0.047 & 1.43 \\
Mean & - & - & - & & 1.08 & 0.95 & 0.064 & 0.010 \\
STD & - & - & - & & 0.11 & 0.06 & 0.010 & 0.26 \\
\hline
\end{tabular}

and population evacuation. But in order to evaluate the potential hazard, and thus the intensity of an event, empirical predictors should be defined and are here presented within the next section.

Except close to impact, where the wave is still forming and the volume is increasing, $V_{w}$ stays almost constant along the wave propagation, being $V_{w} / V_{s}=2.5( \pm 0.14)$. This interesting result confirms that the leading wave almost does not lose volume in favour of the following waves. The landslide energy transfers to the water provoking at first a crater, then a large splash and finally the wave train. Immediately after the crater and the splash are extinguished, it is possible to take a first measurement of the leading wave's characteristics. At this point, called $x_{\max }$ and at time $t_{\max }$, the formed wave is found to be "suspended" at its highest amplitude $a_{\max }$ and it retains mainly potential energy. After this instant, the wave starts to propagate and progressively the potential energy converts into kinetic energy. At the same time that the wave loses potential energy, it also loses amplitude. Close to formation, waves are highly nonlinear. But sufficiently far from the generation point the waves stabilize (Kamphuis \& Bowering, 1970) and begin assuming a linear behaviour (Le Méhauté \& Wang, 1996). The principles of equipartition, $E_{w} \approx 2 E_{w, p o t}$, and conservation of the total energy $E_{w}$ are confirmed by the measurement done in the tank where:

$$
E_{w} \approx E_{w, p o t}\left(x_{\max }\right) \approx 2 E_{w, p o t}\left(x_{f i n}\right)
$$

where $x_{f i n}$ is the farthest available measurement within the wave tank. Results in support of this statement are reported in Table 2. Close to impact the energy equipartition principle is not valid, thus doubling the $E_{w, p o t}$ causes a huge overestimation of energy conversion (Fritz et al., 2004). The efficiency of energy conversion between landslide and first crest is here defined as $\varepsilon=E_{w, p o t}\left(x_{\max }\right) / E_{s, k i n}$. In the present experiments the measured efficiency falls in the range $\varepsilon=[0.047 ; 0.081]$. The values of $\epsilon$ are low. Once the box flaps open at the end of the channel, the granular mass suddenly starts to stretch due to the basal friction with the wedge. At impact with water the granular mass suffers additional deformations, due to the hydrodynamic drag resistance and turbulence at water-solid boundaries, that partially re-compress the mass. These last two effects were not observed due to the absence of underwater records during the landslide propagation. However they are witnessed by the quasielliptical final deposit on the tank bottom. Therefore a large amount of energy is dissipated by landslide basal friction and turbulence. Basal friction, drag and turbulence dissipations will be examined in the next step of this research.

The measurements of $a$ (Fig. 9a and 9b), $v_{w}, V_{w}$ (Fig. 9c) and $E_{w, p o t}$ (Fig. 9d) are performed starting from $x_{\max }$ and $t_{\max }$ where the splash is extinguished, the amplitude is at its maximum and the wave starts to propagate. Being the measurement close to the impact, any effort to fit theoretically the wave behaviour failed. Thus the wave properties have been fitted by empirical predic-tors described hereinafter. Detailed data and graphics for each experimental run are provided in Supplemental Material.

\section{Empirical predictors}

The empirical predictive formulas were determined by multiple regressions of the measured values in dimensionless form. However, the importance of each governing parameter changes, depending on the predicted variable. Thus, only the more relevant governing parameters are taken, case by case, to define simplified empirical formulas. Similarly, all the combinations of parameters are investigated, but only the more relevant are presented. The multiple regressions are performed through an optimization framework to search the best fit with measured data. In order to define tools useful in assessing the risk related to landslide tsunamis, the empirical formulas have been determined to predict: (1) $a_{\max }, x_{\max }, t_{\max }, a(x)$ and $a(t)$ related to the first wave crest; (2) the energy conversion $\epsilon$ between landslide and first wave crest. An appropriate energy parameter suitable to define the energy dimensionless forms is the following:

$$
E_{w, \text { hydrostatic }}=\rho_{w} g w_{s} l_{s} h_{w}^{2} / 2
$$

$E_{w, h y d r o s t a t i c}$ can be seen as the potential hydrostatic energy that opposes the landslide impact energy.

The following formula is selected to represent the $a_{\max }$ :

$$
\frac{a_{\max }}{h_{w}}=0.118\left(\frac{h_{s}}{h_{w}}\right)^{0.459}\left(\frac{l_{s}}{h_{w}}\right)^{0.463} \mathrm{~F}^{0.554}
$$

Equation (14) has a correlation coefficient between measured experimental data and estimated values of $R^{2}=0.924$ and a mean squared error $M S E=0.001$. The location $x_{\max }$ and time $t_{\max }$ where the $a_{\max }$ is verified are predicted with the following 

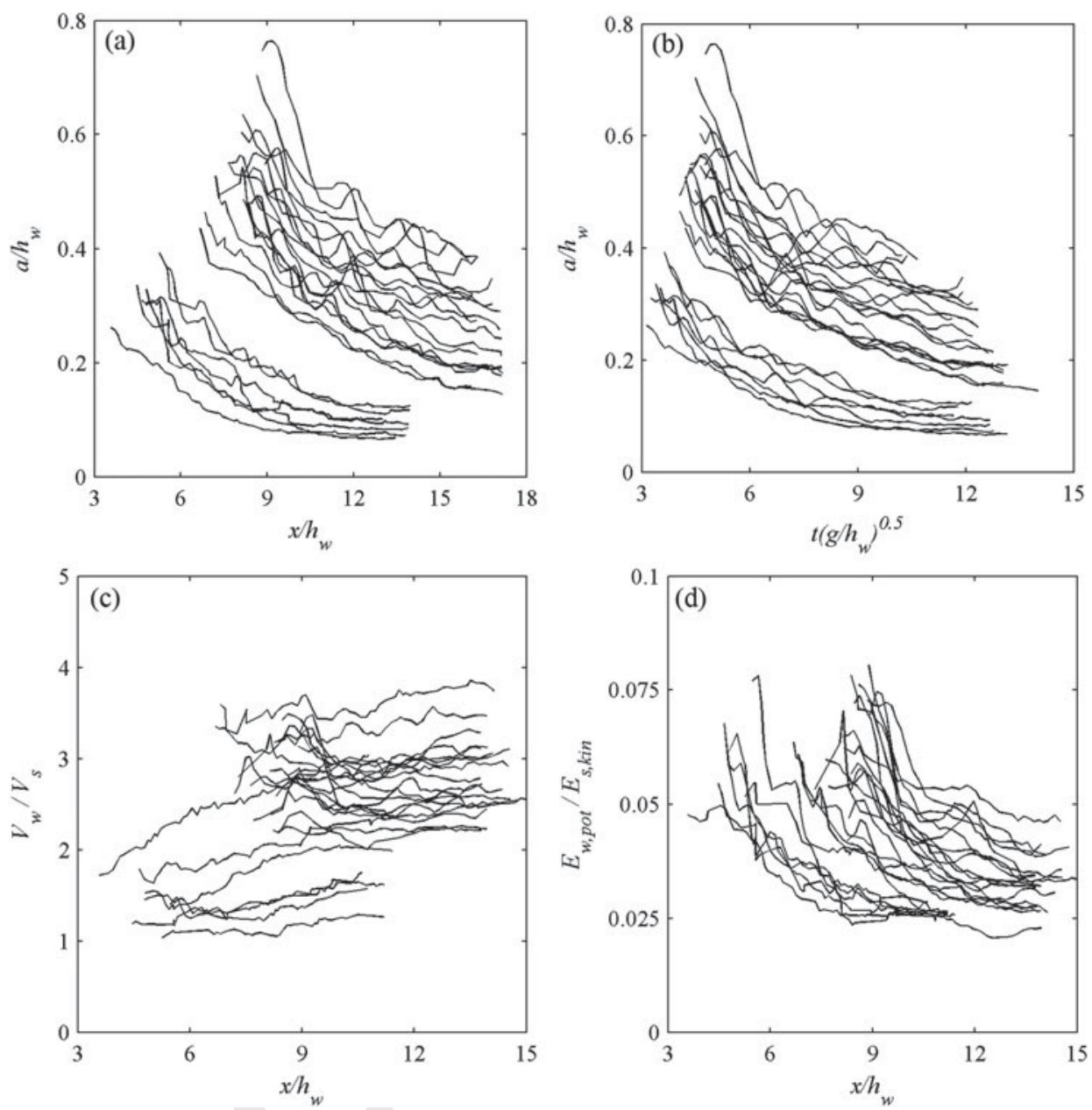

951

956

Figure 9 First wave dimensionless results for all experiments: (a) amplitude in space; (b) amplitude in time; (c) first crest volume; (d) first crest potential energy

formulas:

$$
\begin{aligned}
\frac{x_{\max }}{h_{w}} & =3.97\left(\frac{h_{s}}{h_{w}}\right)^{0.198}\left(\frac{E_{s, \text { kin }}}{E_{w, \text { hydrostatic }}}\right)^{0.277} \\
t_{\max } \cdot\left(\frac{g}{h_{w}}\right)^{1 / 2} & =3.03\left(\frac{h_{s}}{h_{w}}\right)^{0.100}\left(\frac{E_{s, \text { kin }}}{E_{w, \text { hydrostatic }}}\right)^{0.164}
\end{aligned}
$$

Validation and performance of Eqs (14), (15) and (16) are provided in Supplemental Material. The evaluated $x_{\max }$ and $t_{\max }$ together with $a_{\max }$ are the initial conditions of the first crest amplitude propagation which is found to be well fitted by exponential decay formulas in space and time having the following form:

$$
\begin{gathered}
a\left(x / h_{w}\right)=a_{\max } e^{k_{x} \cdot\left(x-x_{\max }\right) / h_{w}}, \quad \text { for } x \geq x_{\max } \\
a\left(t \cdot\left(g / h_{w}\right)^{1 / 2}\right)=a_{\max } e^{k_{t} \cdot\left(t-t_{\max }\right)\left(g / h_{w}\right)^{1 / 2}}, \quad \text { for } t \geq t_{\max }
\end{gathered}
$$

where $k_{x}=-0.102$ and $k_{t}=-0.108$ are the exponential decay constants respectively in space and time. Giving that the exponential decay rates in space and time are found to be similar for all the conducted experiments, the exponential decay constants $k_{x}$ and $k_{t}$ are assessed as the averaged values of all the fitted exponential decay constants in space and time. In Eqs (17) and (18) $a_{\max }$ is estimated by Eq. (14), $x_{\max }$ is estimated by Eq. (15) and $t_{\max }$ is estimated by Eq. (16). Equation (17) entails an $R^{2}=0.842$ and a $M S E=0.003$ between measured data and estimated values (Fig. 10a). Equation (18) entails an $R^{2}=0.865$ and a $M S E=0.002$ between measured data and estimated values (Fig. 10b). While observing Eq. (18) the dimensionless coefficient of amplitude decay in time is equal to -0.108 . A characteristic of exponential decay in time is the time required for the amplitude to fall to $1 / 2$ of its initial value. This time is called half-life and is denoted by the symbol $t_{1 / 2}$. For the presented results the dimensionless half-life may be defined in terms of the constant decay as:

$$
t_{1 / 2} \cdot\left(\frac{g}{h_{w}}\right)^{1 / 2}=\frac{\ln (2)}{k_{t}}=6.42
$$

This result highlights the strong decay that the wave experiences. In our experiment, in those runs where the $h_{w}=0.2 \mathrm{~m}$ the wave decays by $1 / 2$ after less than $1 \mathrm{~s}$. For a hypothetical case where $h_{w}=100 \mathrm{~m}, t_{1 / 2} \approx 20 \mathrm{~s}$.

Experiments on tsunamis generated by granular landslides have been performed by several researchers. Based on a $2 \mathrm{D}$ 
granular landslide wave generator set-up, Heller and Hager (2010) define the following empirical formula for the 2D propagating wave amplitude in space:

$$
\begin{aligned}
& \frac{a\left(x / h_{w}\right)}{h_{w}} \\
& =3 / 5\left\{\left(\frac{h_{s}}{h_{w}}\right)^{1 / 2}\left[\frac{m_{s}}{\left(\rho_{w} w_{s} h_{w}^{2}\right)}\right]^{1 / 4}[\cos (\alpha 6 / 7)]^{1 / 2}\left(\frac{x}{h_{w}}\right)^{-1 / 3} \mathrm{~F}\right\}^{4 / 5}
\end{aligned}
$$

The comparison between the amplitude predicted with Eq. (20) against our experimental results is given in Fig. 11a. One can observe that the formula of Heller and Hager (2010) overestimates our wave amplitude data by 0.5-8.5 times. Although their experimental parameters ranges fit that of our set-up, the amplitude prediction of Eq. (20) is valid for 2D wave generation and propagation, and does not geometrically apply to our 3D set-up. A 2D set-up constrains the formed wave in two directions while in our set-up the wave is free to expand laterally. Therefore, considering the same landslide parameters, the wave amplitude in

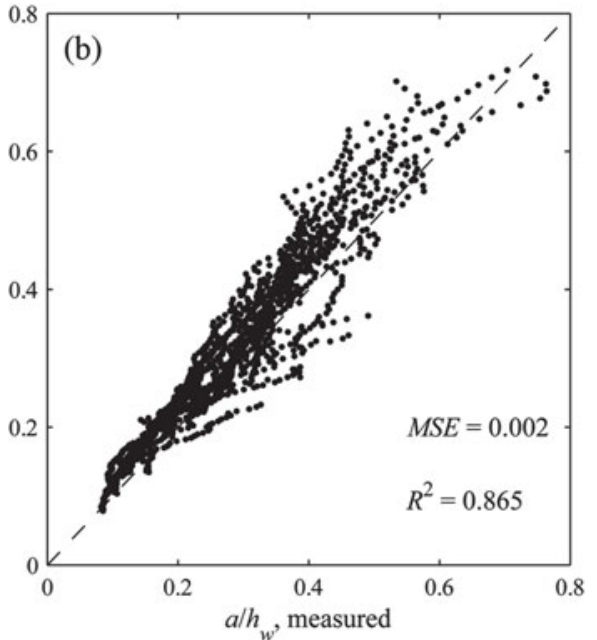

a $2 \mathrm{D}$ configuration is expected higher than in our 3D set-up. A similar result was found by Panizzo et al. (2005b) in their 3D set-up, showing that the earlier 2D formula of Fritz et al. (2004) overestimated their experimental data by 5-40 times. Mohammed and Fritz (2012) used a huge 3D granular landslide wave generator set up to define an empirical formula of $3 \mathrm{D}$ propagating wave amplitude in space as follows:

$\frac{a\left(x / h_{w}\right)}{h_{w}}=0.31 \cdot \mathrm{F}^{2.1}\left(\frac{h_{s}}{h_{w}}\right)^{0.60}\left(\frac{x}{h_{w}}\right)^{-1.2 \mathrm{~F}^{0.25}\left(h_{s} / h_{w}\right)^{-0.02}\left(w_{s} / h_{w}\right)^{-0.33}}$

where only the main direction of propagation $x$ (axial to the landslide propagation) is considered. Equation (21) underestimates our data by $0-0.64$ times (Fig. 11b), performing a better prediction than the Heller and Hager (2010) formula and bearing the 3D behaviour of our set-up. The comparison shows a higher disagreement at bigger wave amplitudes, and thus closer to impact, where the generating mechanism is still dominant. Moreover Eq. (21) has been tested on $a / h_{w}<0.37$, therefore comparison out of this range can be inadequate. 
It was found essential to evaluate the efficiency of energy conversion $\epsilon$ from the kinetic energy of the landslide upon impact $E_{s, k i n}$ to the total energy of the formed leading wave $E_{w}$. Thanks to the presented experimental results, $E_{w}$ can be related to $E_{S, k i n}$ by means of the following relationship:

$$
\frac{E_{w}}{E_{w, \text { hydrostatic }}}=0.140\left(\frac{h_{s}}{l_{s}}\right)^{0.417}\left(\frac{E_{s, \text { kin }}}{E_{w, \text { hydrostatic }}}\right)
$$

Equation (22) entails an $R^{2}=0.934$ and a $\mathrm{MSE}=0.015$ between measured data and estimated values. Validation and performance of Eq. (22) are provided in Supplemental Material. The exponent of $E_{s, k i n}$ has been conveniently taken as 1 to directly obtain the efficiency of energy conversion $\epsilon$ as follows:

$$
\varepsilon=\frac{E_{w}}{E_{s, k i n}}=0.140\left(\frac{h_{s}}{l_{s}}\right)^{0.417}
$$

A sensitivity analysis on the proposed formulas has been performed including artificially the maximum systematic errors in vertical measurements $\left(h_{s}, a\right.$ and $\eta$ ) identified in Section 4 . The empirical formulas of Eqs (14), (15), (17) and (22) are then re-optimized including the mentioned errors. Successively the re-optimized formulas results are compared against the results predicted by the original formulas of Eqs (14), (15), (17) and (22) through the mean relative error $(M R E)$ in \% as a mea-sure of the formula's maximum uncertainty. MRE values for the worst scenarios are $24 \%, 3 \%, 27 \%$ and $40 \%$ respectively for $a_{\max }, x_{\max }, a(x)$ and $E_{w}$. Similar results to that for $x_{\max }$ and $a(x)$ can be found respectively for $t_{\max }$ and $a(t)$. One can observe that the error on $E_{w}$ is considerably higher because it propagates proportionally to $\eta^{2}$ as in Eq. (11).

\section{Test on Chehalis Lake event (Canada, 2007)}

1136 A real event entails complex terrain morphology and geomorphology. Thus, for a detailed analysis, scaled physical models or 3D numerical models should be employed. However, we believe that empirical predictors can be an important tool for a rapid estimation of the potential effects of landslide tsunamis. Thus,

1141 to evaluate their predictive capability and usability, the proposed empirical formulas are here applied on a past event.

A recent and well-documented example of tsunamigenic landslide, triggered by water infiltration, is the event of Chehalis Lake (Canada). The landslide occurred on 4 December 2007 , 1146 when rainfall combined with snow melting increased the soil pore pressure and triggered the landslide. The mass released by the failure, with a volume in the order of $3 \times 10^{6} \mathrm{~m}^{3}$, entered the lake, provoking a tsunami wave that buried three local camp-grounds and stripped the vegetation on the opposite shore of the lake to a maximum height of $38 \mathrm{~m}$. Fortunately no casualties were incurred as the campgrounds were operating in low-season. Detailed field measurements, terrestrial photogrammetric 3D models and an airborne LiDAR digital elevation model were conducted to describe the landslide pre- and postevent as well as the mechanism of failure (Brideau et al., 2012). Following the observations of Brideau et al. (2012), Roberts et al. (2013) and Lawrence, Roberts, and Clague (2013), the landslide had a rock density of $2700 \mathrm{~kg} \mathrm{~m}^{-3}$, a mean thickness of $40 \mathrm{~m}$, a width of $210 \mathrm{~m}$ and an angle of impact of $30^{\circ}$. The mean landslide length is estimated at $375 \mathrm{~m}$ using the mentioned volume, thickness and width. The bulk density of landslide $\rho_{s, b u l k}$ can be estimated at $1650 \mathrm{~kg} \mathrm{~m}^{-3}$ after considering a porosity of $40 \%$. On the day of the event the lake had a depth of $175 \mathrm{~m}$. The landslide velocity was estimated having a maximum value of $60 \mathrm{~m} \mathrm{~s}^{-1}$ by Wang, Ward, and Xiao (2015). The maximum runup of $38 \mathrm{~m}$ was observed on the flank of the lake opposite to the landslide, where the lake width is $700 \mathrm{~m}$. The flank where the $38 \mathrm{~m}$ run-up was observed has a slope of approximately $28.5^{\circ}$. Flank slope and distance are obtained from Google Earth ( (map from 2010, Fig. 12). Table 3 displays a summary of the test case data. Associated dimensionless parameters are $\mathrm{F}=$ $1.45, h_{s} / h_{w}=0.23, l_{s} / h_{w}=2.15$ and $a / h_{w} \approx 0.10$ (see the following results). Although $\mathrm{F}, h_{s} / h_{w}$ and $l_{s} / h_{w}$ are out of the experimental range (see Tables 1 and 2), the case study is undertaken because its behaviour is similar to the experimental behaviour. Further-more, among the literature empirical predictors have been tested on past events well out of the experimental ranges (e.g. Fritz, Mohammed, \& Yoo, 2009; Panizzo, De Girolamo, Di Risio, Maistri, \& Petaccia, 2005a).

On the basis of the above data, the calculation of the maximum first wave amplitude was performed using Eq. (14), resulting in $a_{\max }=18 \mathrm{~m}$ at a distance $x_{\max }=500 \mathrm{~m}$ and at a time $t_{\max }=11 \mathrm{~s}$ from impact. It should be noted that $x_{\max }$ was calculated with Eq. (15) and $t_{\max }$ with Eq. (16). Being the distance from landslide impact to the opposite lake shorelines $x_{\text {hit }}=700 \mathrm{~m}$ along the landslide axial direction (see Fig. 12), the wave amplitude is evaluated taking into account the amplitude decay. Equation (17) was used to evaluate $a\left(x_{h i t}\right)$, employing the computed $a_{\max }=18 \mathrm{~m}$ and $x_{\max }=500 \mathrm{~m}$. The resulted amplitude is $a\left(x_{h i t}\right)=16 \mathrm{~m}$. An attempt was performed to measure the wave run-up using the wave decay in time. Using the approximation of the celerity of a solitary wave, earlier found to be representative of the leading crest celerity, it is possible to estimate the time that the leading crest takes from the position and instant of its maximum amplitude $\left(x_{\max }=500 \mathrm{~m}\right.$ and $\left.t_{\max }=11 \mathrm{~s}\right)$ to hit the opposite shoreline. Finally the formula to estimate the elapsed time $t_{h i t}$ from landslide impact to the time when the tsunami hit the opposite shoreline is as follows:

$$
\begin{aligned}
t_{\text {hit }} & =t_{\max }+\frac{x_{\text {hit }}-x_{\max }}{c_{\text {sol }}}=t_{\max }+\frac{x_{\text {hit }}-x_{\max }}{\left[g \cdot\left(h_{w}+a_{\max }\right)\right]^{1 / 2}} \\
& =11+\frac{700-500}{[9.81 \cdot(175+18)]^{1 / 2}}=15.6 \mathrm{~s}
\end{aligned}
$$

With this time estimation Eq. (18) was used to evaluate $a\left(t_{h i t}\right)$ employing the computed $a_{\max }=18 \mathrm{~m}$ and $t_{\max }=11 \mathrm{~s}$. The resulting amplitude is $a\left(t_{\text {hit }}\right)=16 \mathrm{~m}$. 


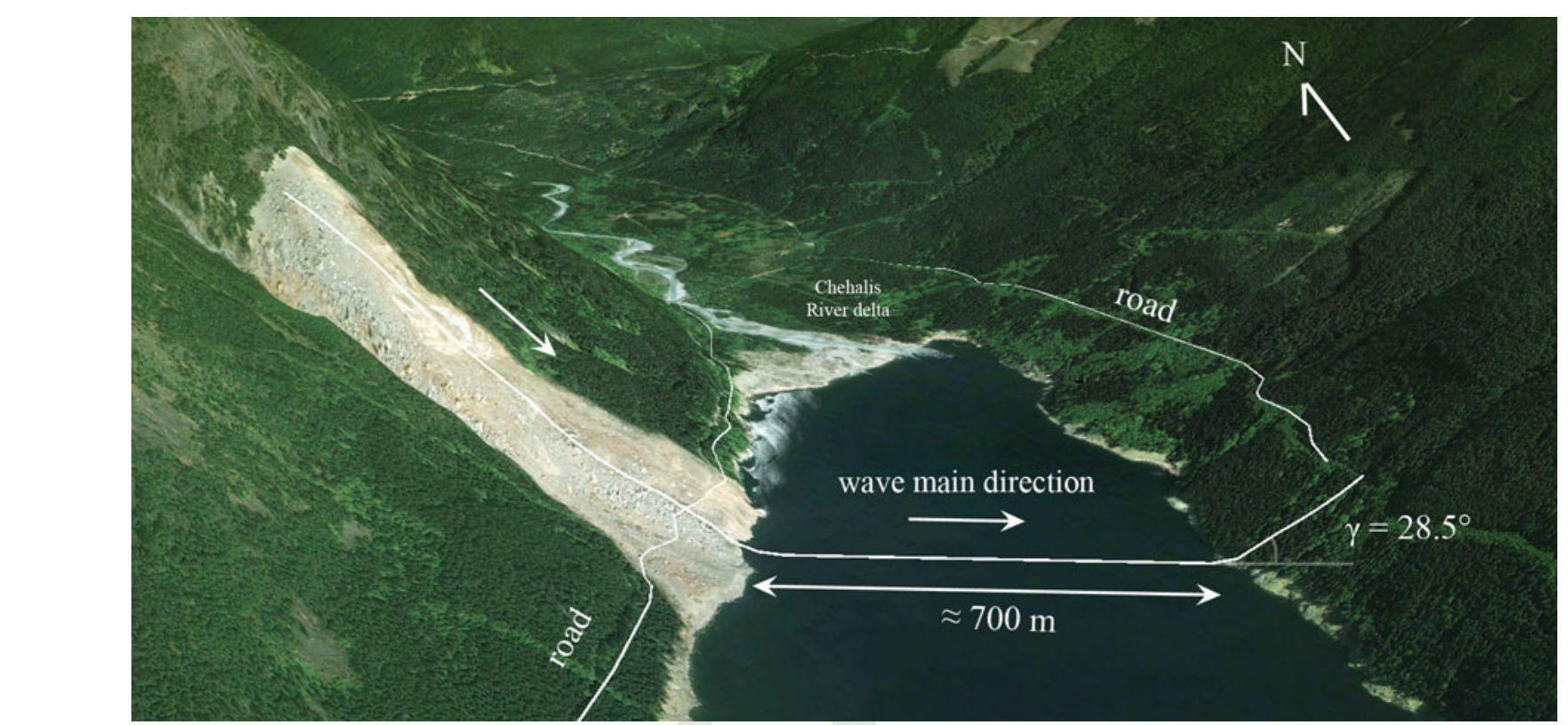

Figure 12 Sketch of 2007 Lake Chehalis event. Oblique photo taken from Google Earth® (image of 2010, accessed in 2015)

$1231^{\text {Table } 3}$ Summary of the 2007 Lake Chehalis event data

\begin{tabular}{ccccccccccc}
\hline$V_{s}\left(\mathrm{Mm}^{3}\right)$ & $\begin{array}{c}\rho_{s, \text { bulk }} \\
\left(\mathrm{kg} \mathrm{m} \mathrm{m}^{-3}\right)\end{array}$ & $h s(\mathrm{~m})$ & $w_{s}(\mathrm{~m})$ & $l_{S}(\mathrm{~m})$ & $v_{s}\left(\mathrm{~ms}^{-1}\right)$ & $\alpha\left(^{\circ}\right)$ & $h_{w}(\mathrm{~m})$ & $x_{\text {hit }}(\mathrm{m})$ & $\gamma\left({ }^{\circ}\right)$ & $R u(\mathrm{~m})$ \\
\hline 3 & 1650 & 40 & 210 & 375 & 60 & 30 & 175 & 700 & 28.5 \\
\hline
\end{tabular}

The transformation from amplitude to the run-up $R u$ has been done using two different approaches. The first uses the empirical formula of Hall and Watts (1953):

$$
\frac{R u}{h_{w}}=3.05 \gamma^{-0.13}\left(\frac{a_{s o l}}{h_{w}}\right)^{1.15 \gamma^{0.2}}
$$

valid for the run-up of a solitary wave of amplitude $a_{\text {sol }}$ along an impermeable flank of slope $\gamma$. Equation (25) has ranges of validity $12^{\circ}<\gamma<45^{\circ}$ and $0.1<R u / h_{w}<1$ which correspond to $17.5 \mathrm{~m}<R u<175 \mathrm{~m}$ for the Chehalis water depth case. The second approach uses the formula of Synolakis (1987):

$$
\frac{R u}{h_{w}}=2.831(\cot \gamma)^{1 / 2}\left(\frac{a_{s o l}}{h_{w}}\right)^{5 / 4}
$$

valid for the run-up of a solitary wave of amplitude $a_{\text {sol }}$ along an impermeable flank of slope $\gamma$. Equation (26) is an approximated solution of linear and nonlinear theories. The formula has been successfully tested on several exper-iments. The ranges of test indicated in Synolakis (1987) are $3^{\circ}<\gamma<$ $45^{\circ}$ and $0.02<R u / h_{w}<1$, which correspond to $3.5 \mathrm{~m}<R u<$ $175 \mathrm{~m}$ for the Chehalis water depth case. Both approaches ranges of validity cover the Chehalis case. Equation (25), with $a_{\text {sol }}=a\left(x_{h i t}\right)=16 \mathrm{~m}, h_{w}=175 \mathrm{~m}$ and $\gamma=28.5^{\circ}$, gives $R u=39$ m. Equation (26), with $a_{s o l}=a\left(x_{h i t}\right)=16 \mathrm{~m}, h_{w}=175 \mathrm{~m}$ and $\gamma$ $=28.5^{\circ}$, gives $R u=34 \mathrm{~m}$. Equation (25), with $a_{s o l}=a\left(t_{h i t}\right)=$ $16 \mathrm{~m}, h_{w}=175 \mathrm{~m}$ and $\gamma=28.5^{\circ}$,
Table 4 Main results and comparisons of wave amplitude and run-up at opposite shoreline after applying various predictive empirical equations on 2007 Lake Chehalis event

\begin{tabular}{lccccc}
\hline Reference & $\begin{array}{c}\text { Equation } \\
\text { number }\end{array}$ & $a\left(x_{\text {hit }}\right)(\mathrm{m})$ & $a\left(t_{\text {hit }}\right)(\mathrm{m})$ & $R u^{*}(\mathrm{~m})$ & $R u^{* *}(\mathrm{~m})$ \\
\hline $\begin{array}{l}\text { This study } \\
\text { Heller and }\end{array}$ & $(17)$ & 16 & & 39 & 34 \\
$\quad \begin{array}{l}\text { Hager } \\
(2010)\end{array}$ & & 49 & & 164 & 138 \\
$\begin{array}{c}\text { Mohammed } \\
\text { and Fritz } \\
(2012)\end{array}$ & $(21)$ & 8 & & 28 & 15 \\
This study & $(18)$ & & & & \\
\hline
\end{tabular}

*Run-up as calculated with Eq. (25).

**Run-up as calculated with Eq. (26).

gives $R u=38 \mathrm{~m}$. Equation (26), with $a_{\text {sol }}=a\left(t_{h i t}\right)=16 \mathrm{~m}, h_{w}=$ $175 \mathrm{~m}$ and $\gamma=28.5^{\circ}$, gives $R u=34 \mathrm{~m}$. These run-up values are very close to that observed around the area hit by the wave along the landslide axial direction.

Table 4 shows test case results and comparisons of predicted wave amplitude and run-up applying various empirical formulas including that of this study, Heller and Hager (2010) and Mohammed and Fritz (2012). As disclosed in Section 6, Eq. (20) (Heller \& Hager, 2010) overestimates considerably the wave amplitude, revealing a run-up of three to six times higher than the observed. Conversely, Eq. (21) (Mohammed \& Fritz, 2012) underestimates the observed run-up by a factor ranging from 
13210.4 to 0.73 . Beyond the formulas limitations and differences exposed in Section 6, it must be said that the Chehalis Lake test case involves a relative distance of propagation $x_{h i t} / h_{w}=4$, shorter than the minimum distance of validity of Eqs (20) and (21), being respectively $x / h_{w}=5.5$ and $x / h_{w}=19$. However, the 1326 formulas of this work are valid for $x / h_{w}>3.58$ and are well suitable to predict the case study wave.

\section{Conclusions}

With the objective of studying the phenomena of tsunamis generated by high speed granular landslides, a new experimental set-up was designed to reproduce what had been identified as the main issues to be addressed: three-dimensional granular landslide deformation and three-dimensional wave propagation. A new versatile measuring system based on computer vision techniques was set up to observe the mass movement and the wave propagation continuously in time and space, avoiding the classic spot measures given by probes. A total of 41 experiments were carried out varying velocity, angle of impact, mass, thickness and length of landslide. The main results are:

- The volume and energy of the leading wave crest are practically conserved during wave propagation. The efficiency of energy conversion between landslide and tsunami is found to be low, spanning from 0.047 to 0.081 . The remaining landslide energy is lost by dissipative effects.

- The celerity of the first crest is comparable with that of solitary waves.

- Empirical predictors have been defined through multivariable regressions. The empirical formulas give the predictions for the following tsunami leading wave crest characteristics: maximum wave amplitude, location and time of the maximum wave amplitude, amplitude decay in space and time and energy conversion.

- The analysis of the first crest amplitude evolution shows that after its maximum condition, given at a certain location and time by the generation features, the amplitude starts to rapidly decay exponentially along the propagation following the rule $a(x) / h_{w} \propto e^{-0.1 x / h_{w}}$. A similar conclusion can be drawn for the first crest propagation in time.

- All the empirical formulas were tested on the experimental dataset, resulting in high correlation between measured and predicted values. The predictive formulas are successfully applied to the 2007 event of Lake Chehalis (Canada).

The studies contained in this work present some limitations. In evaluating the experimental results, only the data corresponding to the main wave direction of propagation (axial to the landslide motion) are analysed. This means that the proposed empirical formulas are suitable within a 3D water body but they can assess the wave characteristics only along the main wave direction of propagation. In evaluating the volume and the energy of the first crest, a constant wave amplitude of the wave front was considered. Further observation should be devoted to the wave angular attenuation. In limited experiments it was possible to evaluate the wave lateral expansion, noting that the wave front has a semi-elliptical form. Due to the limited size of the wave tank, only the signal relative to the first wave crest is clean and analysable, while the rest is compromised by lateral and frontal reflections. However it was demonstrated that the lead-ing wave contains more than $90 \%$ of the total wave train energy (Law \& Brebner, 1968). Only a minor amount of energy passes from the leading wave to the wave train. This behaviour is par-tially confirmed by the steadiness of the wave volume along the propagation found in the present work. Therefore the first wave crest data entails the most important features with regards to hazard. It was herein proved that the predictive tools are able to quantify the potential hazard posed by landslide generated tsunamis, and that they can be useful in risk-assessment frameworks.

\section{Acknowledgements}

Special thanks are addressed to Prof. Hermann Fritz (GeorgiaTech) for his collaboration in training FB regarding the topic of landslide tsunami. The authors would like to sincerely thank Manuel Rast (former student at ETH-Zurich and Erasmus Programme Exchange student at UPC) for helping in the initial set-up.

\section{Funding}

The laboratory set-up was funded by the three-year national project DEBRIS FLOW [grant number CGL 2009-13039] of the Spanish Ministry of Education. This work was partly supported by the four-yearproject [grant number FPU2009] of the Span-ish Ministry of Education given to FB, Ministerio de Ciencia e Innovación.

\section{Supplemental data}

Supplemental data for this article can be accessed doi:10.1080/ 00221686.2017 .1289259 .

\section{Notation}

$a \quad=$ wave amplitude of the first crest (m)

$a_{d} \quad=$ major axis of the final deposit of the landslide (m)

$a_{\max }=$ maximum wave amplitude $(\mathrm{m})$

$a_{\text {sol }} \quad=$ amplitude of solitary wave (m)

$b_{d} \quad=$ minor axis of the final deposit of the landslide (m)

$c \quad=$ shallow water wave celerity $\left(\mathrm{m} \mathrm{s}^{-1}\right)$

$c_{\text {sol }} \quad=$ solitary wave celerity $\left(\mathrm{m} \mathrm{s}^{-1}\right)$ 
1431

$d_{50}$

$=$ median grain diameter of the sliding material $(\mathrm{mm})$

D = distance of the landslide final deposit's farthest grain (m)

$E_{S, k i n} \quad=$ landslide kinetic energy $(\mathrm{J})$

1436

$E_{w} \quad=$ wave first crest total energy $(\mathrm{J})$

$E_{w, p o t}=$ wave first crest potential energy $(\mathrm{J})$

$E_{w, \text { hydrostatic }}=$ hydrostatic energy of still water $(\mathrm{J})$

$\mathrm{F} \quad=$ Froude number of landslide $(-)$

$g \quad=$ gravity acceleration $\left(\mathrm{m} \mathrm{s}^{-2}\right)$

$h \quad=$ wave height $(\mathrm{m})$

$h_{s} \quad=$ average thickness of the landslide $(\mathrm{m})$

$h_{w} \quad=$ water depth $(\mathrm{m})$

$k_{x} \quad=$ exponential decay constant in space $(-)$

$k_{t} \quad=$ exponential decay constant in time $(-)$

$l \quad=$ wavelength $(\mathrm{m})$

$L \quad=$ water tank length $(\mathrm{m})$

$l_{1 c} \quad=$ length of the 1 st crest of the wave $(\mathrm{m})$

$l_{s} \quad=$ length of the landslide $(\mathrm{m})$

$M \quad=$ total mass of granular material per width unit and density unit $\left(\mathrm{m}^{2}\right)$

$=$ mass of the sliding material $(\mathrm{kg})$

$=$ factor of shape of elliptical wave front $(-)$

$=$ wave first up-crossing point

$=$ wave first down-crossing point

$=$ momentum of granular material per width unit and density unit $\left(\mathrm{m}^{3} \mathrm{~s}^{-1}\right)$

$=$ impulsive Reynolds number $(-)$

$=\operatorname{run}-u p(\mathrm{~m})$

$=$ elapsed time from landslide impact ( $\mathrm{s}$ )

$=$ elapsed time from landslide impact of the maximum wave amplitude (s)

$=$ velocity of the landslide $\left(\mathrm{m} \mathrm{s}^{-1}\right)$

$=$ celerity of the first wave crest $\left(\mathrm{m} \mathrm{s}^{-1}\right)$

$=$ volume of the landslide $\left(\mathrm{m}^{3}\right)$

$=$ volume of wave first crest $\left(\mathrm{m}^{3}\right)$

$=$ water tank width $(\mathrm{m})$

$=$ impulsive Weber number $(-)$

$=$ width of landslide $(\mathrm{m})$

$=$ distance from the impact along sliding direction (m)

$=$ distance from the impact of the farthest available measurement along sliding direction (m)

$=$ distance from the impact of the maximum wave amplitude (m)

$=$ point of landslide entrance in the water body, and origin of measurements

$=$ lateral distance from sliding direction $(\mathrm{m})$

$=$ impact angle $(-)$

$\gamma \quad=$ run-up slope $(-)$

148

$\Delta t_{H D} \quad=$ frame period (time interval between frames) of the HD camera (s)

$\Delta t_{H S} \quad=$ frame period (time interval between frames) of the HS camera (s)

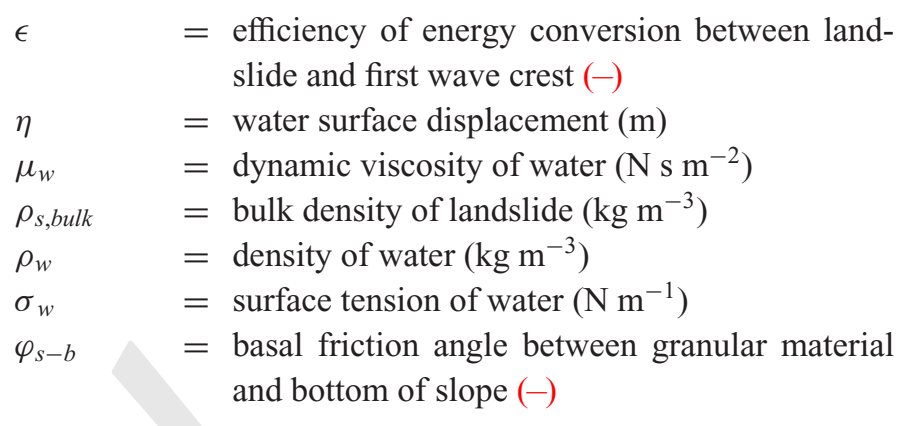

\section{ORCID}

Francesco Bregoli (iD http://orcid.org/0000-0003-0336-3942

Allen Bateman Pinzón (D) http://orcid.org/0000-0001-9980-6554

\section{References}

Abadie, S., Morichon, D., Grilli, S., \& Glockner, S. (2010). Numerical simulation of waves generated by landslides using a multiple-fluid Navier-Stokes model. Coastal Engineering, 57(9), 779-794.

Ataie-Ashtiani, B., \& Nik-Khah, A. (2008). Impulsive waves caused by subaerial landslides. Environmental Fluid Mechanics, 8(3), 263-280.

Bardet, J.-P., Synolakis, E. C., Davies, L. H., Imamura, F., \& Okal, A. E. (2003). Landslide tsunamis: Recent findings and research directions. Pure and Applied Geophysics, 160(10), 1793-1809.

Bateman, A., Granados, A., Medina, V., Velasco, D., \& Nalesso, M. (2006). Experimental procedure to obtain 2D timespace high-speed water surfaces. In R. Ferreira (Eds.), River flow: Proceedings of the international conference on fluvial hydraulics (pp. 1879-1888). Lisbon: Taylor \& Francis.

Brideau, M.-A., Sturzenegger, M., Stead, D., Jaboyedoff, M., Lawrence, M., Roberts, N. J., ... Clague, J. J. (2012). Stability analysis of the 2007 Chehalis lake landslide based on long-range terrestrial photogrammetry and airborne LiDAR data. Landslides, 9(1), 75-91.

Carvalho, R. F., \& Antunes do Carmo, J. S. (2007). Landslides into reservoirs and their impacts on banks. Environmental Fluid Mechanics, 7(6), 481-493.

Erikson, L. H., \& Hanson, H. (2005). A method to extract wave tank data using video imagery and its comparison to conventional data collection techniques. Computers \& Geosciences, 31(3), 371-384.

Fritz, H. M., Hager, W. H., \& Minor, H.-E. (2003a). Landslide generated impulse waves. 1. Instantaneous flow fields. Experiments in Fluids, 35(6), 505-519.

Fritz, H. M., Hager, W. H., \& Minor, H.-E. (2003b). Landslide generated impulse waves. 2. Hydrodynamic impact craters. Experiments in Fluids, 35(6), 520-532.

Fritz, H. M., Hager, W. H., \& Minor, H.-E. (2004). Near field characteristics of landslide generated impulse waves. Journal of Waterway, Port, Coastal, and Ocean Engineering, 130(6), 287-302.

148

149

149 
1541 Fritz, H. M., Mohammed, F., \& Yoo, J. (2009). Lituya Bay landslide impact generated mega-tsunami 50th anniversary. Pure and Applied Geophysics, 166(1), 153-175.

Hall Jr, J. V., \& Watts, G. M. (1953). Laboratory investigation of the vertical rise of solitary waves on impermeable slopes (Technical Report No. TM33). Washington, DC: Army Coastal Engineering Research Center.

Heller, V. (2011). Scale effects in physical hydraulic engineering models. Journal of Hydraulic Research, 49(3), 293-306.

Heller, V., \& Hager, W. (2010). Impulse product parameter in landslide generated impulse waves. Journal of Waterway, Port, Coastal, and Ocean Engineering, 136(3), 145-155.

Heller, V., Hager, W. H., \& Minor, H.-E. (2008). Scale effects in subaerial landslide generated impulse waves. Experiments in Fluids, 44(5), 691-703.

Heller, V., \& Spinneken, J. (2013). Improved landslide-tsunami prediction: Effects of block model parameters and slide model. Journal of Geophysical Research: Oceans, 118(3), 1489-1507.

Hermanns, R. L., L'Heureux, J.-S., \& Blikra, L. H. (2013). Landslide triggered tsunami, displacement wave. In P. Bobrowsky (Eds.), Encyclopedia of natural hazards, encyclopedia of earth sciences series (pp. 611-615). Springer.

Huber, A. (1980). Schwallwellen in Seen als Folge von Felsstürzen. In D. Vischer (Ed.), VAW-Mitteilung, Volume 47. Versuchsanstalt für Wasserbau, Hydrologie und Glaziologie, ETH Zürich. (In German)

Kamphuis, J. W., \& Bowering, R. J. (1970). Impulse waves generated by landslides. Proceedings 12th Coastal Engineering Conference ASCE, Volume 1 (pp. 575-588). Washington, DC.

Keulegan, G. H. (1948). Gradual damping of solitary waves. Journal of Research of the National Bureau of Standards, 40(6), 487-498.

Law, L., \& Brebner, A. (1968). On water waves generated by landslides. Proceedings of the Third Australasian Conference on Hydraulics and Fluid Mechanics (pp. 155-159).

Lawrence, M. S., Roberts, N. J., \& Clague, J. J. (2013). The 2007 Chehalis Lake landslide, British Columbia: A landslidegenerated surge wave (tsunami) with implications for dam safety. In Geo-montreal.

Le Méhauté, B., \& Wang, S. (1996). Water waves generated by underwater explosion. Advanced Series on Ocean Engineering. Singapore: World Scientific.

Mader, C. (1999). Modeling the 1958 Lituya Bay mega-tsunami. Science of Tsunami Hazards, 17(1), 57-67.

Mazzanti, P., \& De Blasio, F. V. (2011). The dynamics of coastal landslides: Insights from laboratory experiments and theoretical analyses. Bulletin of Engineering Geology and the Environment, 70(3), 411-422.

1591 Mohammed, F., \& Fritz, H. M. (2012). Physical modeling of tsunamis generated by three-dimensional deformable granular landslides. Journal of Geophysical Research: Oceans, 117(C11), C11015.
Panizzo, A., De Girolamo, P., Di Risio, M., Maistri, A., \& Petaccia, A. (2005a). Great landslide events in Italian artificial reservoirs. Natural Hazards and Earth System Science, 5(5), 733-740.

Panizzo, A., De Girolamo, P., \& Petaccia, A. (2005b). Forecasting impulse waves generated by subaerial landslides. Journal of Geophysical Research, 110(C12025), C12025.

Quecedo, M., Pastor, M., \& Herreros, M. (2004). Numerical modelling of impulse wave generated by fast landslides. International Journal for Numerical Methods in Engineering, 59(12), 1633-1656.

Roberts, N. J., McKillop, R. J., Lawrence, M. S., Psutka, J. F., Clague, J. J., Brideau, M.-A., \& Ward, B. C. (2013). Impacts of the 2007 landslide-generated tsunami in Chehalis Lake, Canada. In Landslide science and practice (pp. 133-140). Springer.

Roberts, N., McKillop, R., Hermanns, R., Clague, J., \& Oppikofer, T. (2014). Preliminary global catalogue of displacement waves from subaerial landslides. In K. Sassa, P. Canuti, \& Y. Yin (Eds.), Landslide science for a safer geoenvironment (pp. 687-692). Springer International Publishing.

Sælevik, G., Jensen, A., \& Pedersen, G. (2009). Experimental investigation of impact generated tsunami; related to a potential rock slide, Western Norway. Coastal Engineering, 56(9), 897-906.

Shapiro, L., \& Stockman, G. (2001). Computer vision. Prentice Hall.

Synolakis, C. E. (1987). The runup of solitary waves. Journal of Fluid Mechanics, 185, 523-545.

Tsai, R. (1987). A versatile camera calibration technique for high-accuracy 3D machine vision metrology using off-theshelf TV cameras and lenses. IEEE Journal on Robotics and Automation, 3(4), 323-344.

Vacondio, R., Mignosa, P., \& Pagani, S. (2013). 3D SPH numerical simulation of the wave generated by the Vajont rockslide. Advances in Water Resources, 59, 146-156.

Wang, C.-C., Chen, P.-C., \& Liao, C.-Y. (2012). Application of CCD cameras as a versatile measurement tool for flume tank. Ocean Engineering, 42, 71-82.

Wang, J., Ward, S. N., \& Xiao, L. (2015). Numerical simulation of the December 4, 2007 landslide-generated tsunami in Chehalis Lake, Canada. Geophysical Journal International, 201(1), 372-376.

Ward, S., \& Day, S. (2001). Cumbre Vieja volcano-potential collapse and tsunami at La Palma, Canary Islands. Geophysical Research Letters, 28(17), 3397-3400.

Yao, A., \& Wu, C. H. (2005). An automated image-based technique for tracking sequential surface wave profiles. Ocean Engineering, 32(2), 157-173.

Zhao, T., Utili, S., \& Crosta, G. B. (2016). Rockslide and impulse wave modelling in the Vajont reservoir by DEMCFD analyses. Rock Mechanics and Rock Engineering, 49(6), 2437-2456. 